\title{
Dexmedetomidine enhances hypoxia-induced cancer cell progression
}

\author{
HUA YAN CHEN ${ }^{1}$, GENG HUA LI ${ }^{2}$, GUO CHENG TAN ${ }^{2}$, HUA LIANG ${ }^{1}$, \\ XIAO HONG LAI ${ }^{1}$, QIONG HUANG ${ }^{3}$ and JI YING ZHONG ${ }^{1}$ \\ ${ }^{1}$ Department of Anesthesiology, Affiliated FoShan Hospital of Sun Yat-Sen University, Foshan, Guangdong 528000; \\ ${ }^{2}$ Department of Anesthesiology, Affiliated Luoding Hospital of Guangdong Medical University, Luoding, \\ Guangdong 527200; ${ }^{3}$ Department of Medical Statistics, Affiliated Chancheng Central Hospital of \\ Guangdong Medical University, Foshan, Guangdong 528000, P.R. China
}

Received July 5, 2018; Accepted September 16, 2019

DOI: $10.3892 /$ etm.2019.8136

\begin{abstract}
Dexmedetomidine (DEX) is widely used in perioperative settings for analgesia and sedation; however, little is known about its effects on the hypoxia-induced progression of tumor cells. In the present study, the effects of DEX on hypoxia-induced growth and metastasis of lung cancer cells and colorectal cancer cells was examined. A549 cells and HCT116 cells were treated with normoxia, hypoxia, co-treatment of hypoxia and DEX, and atipamezole (an $\alpha_{2}$ adrenoceptor antagonist) for $4 \mathrm{~h}$. The proliferation rate of cells was determined by MTT assays. Cell metastatic potential was evaluated by Transwell assays. Survivin and hypoxia inducible factor (HIF)-1 $\alpha$ were detected by western blotting. Matrix metalloproteinase (MMP)-2 and MMP-9 were measured using reverse transcription-quantitative PCR. It was demonstrated that hypoxia treatment promoted the proliferation and may promote the metastasis of the two cancer cell lines. DEX substantially contributed to the survival and aggressiveness of the two cancer cell lines following hypoxia. Furthermore, DEX upregulated the expression of survivin, MMP-2, MMP-9 and HIF-1 $\alpha$ in the two cancer cell lines in response to hypoxia. Finally, the effects of DEX on the hypoxia-induced growth and metastatic potential of cancer cells were reversed by atipamezole. Collectively, DEX enhances the hypoxia-induced progression of lung cancer cells and colorectal cancer cells by regulating HIF- $1 \alpha$ signaling, which may be associated with the $\alpha_{2}$ adrenoceptor pathway.
\end{abstract}

Correspondence to: Dr Hua Liang or Dr Ji Ying Zhong, Department of Anesthesiology, Affiliated FoShan Hospital of Sun Yat-Sen University, 81 Lingnan Avenue, Chancheng, Foshan, Guangdong 528000, P.R. China

E-mail: 1hlh2003@126.com

E-mail: zjy@fsyyy.com

Key words: hypoxia, cancer cell, dexmedetomidine

\section{Introduction}

Globally, the number of cancer cases rose by $33 \%$ between 2005 and 2015, and the morbidity and mortality of cancer increases year on year (1). Data, derived from the latest global cancer statistics, indicates lung cancer is the most common diagnosis of cancer (11.6\% of total cases) and the main cause of cancer death (18.4\% of total cancer deaths). Colorectal cancer is also common (6.1\% of total cases) and is a major cause of cancer-related deaths ( $9.2 \%$ of total cases) (2). Surgery is the mainstay treatment strategy for patients with lung and colorectal cancer. Unfortunately, metastatic recurrence after tumor resection remains common and carries a high risk of mortality (3). Preventing tumor cells disseminating during surgery still poses a major challenge for perioperative clinicians.

Hypoxia is one of the typical characteristics of solid tumors due to the excessive proliferation of cancer cells and their increasing oxygen consumption (4). It is well established that hypoxia promotes survival and increases the invasive ability of cancer cells (5). Secondary hypoxia as a result of treatment with anesthetic drugs or anesthetic techniques is a common event during the perioperative period $(6,7)$. Recent findings have suggested that anesthetic drugs might have a significant impact on cancer invasion and progression $(8,9)$. However, the effects of anesthetic agents on the aggressiveness of cancer cells in hypoxia are still largely undefined.

Dexmedetomidine (DEX), a highly selective $\alpha_{2}$-adrenergic receptor agonist, is used in clinical anesthesia settings as both a sedative and analgesic agent. Compelling evidence exists that demonstrates that DEX is able to exert an anti-apoptotic and protective function on cells and organs (10-13); however, the effects of DEX on the invasiveness of cancer cells remains unknown. Several studies have reported that DEX contributes to the growth and metastatic potential of breast cancer cells (14-16). On the contrary, Deng et al (17) found that DEX has no effect on the migration of colorectal cancer cells. Atipamezole, a selective and specific $\alpha_{2}$ receptor-antagonist, has been identified as a drug capable of reversing DEX-induced effects (18). In the present study atipamezole was used as a control for DEX during the observation of the effect of DEX 
on hypoxia-induced growth and the metastatic potential of cancer cells.

In the present study, the effects of DEX on the progression of cancer cells were investigated in the context of hypoxia. Our results revealed that DEX promotes hypoxia-induced growth and may promote the metastasis of lung cancer cells and colorectal cancer cells by regulating hypoxia inducible factor (HIF)-1 $\alpha$ signaling, which may be associated with the $\alpha_{2}$ adrenoceptor-dependent pathway.

\section{Materials and methods}

Cell culture. The human lung adenocarcinoma A549 cell line and human colorectal cancer cell line HCT116 were obtained from the Cell Bank of Type Culture Collection of the Chinese Academy of Sciences. A549 cells and HCT116 cells were cultured in DMEM (Thermo Fisher Scientific, Inc.) supplemented with $10 \%$ FBS (Thermo Fisher Scientific, Inc.), $100 \mathrm{U} / \mathrm{ml}$ penicillin and $100 \mu \mathrm{g} / \mathrm{ml}$ streptomycin under a humidified atmosphere of $5 \% \mathrm{CO}_{2}$ at $37^{\circ} \mathrm{C}$. The media was replaced every 2 or 3 days. Cells were passaged three times a week by treating with trypsin-EDTA. Cells in the logarithmic growth phase were used for the experiments.

Cell treatment. For hypoxia incubation, cells were cultured in airtight glass chambers that were infused with a mixture of $1 \%$ $\mathrm{O}_{2}, 5 \% \mathrm{CO}_{2}$ and $94 \% \mathrm{~N}_{2}$ at $37^{\circ} \mathrm{C}$ as described previously (19). A concentration of $1 \% \mathrm{O}_{2}$ was chosen because it is a classical model for hypoxic insult to cells $(20,21)$. The re-oxygenation treatment after hypoxia was performed by incubating the cells at $37^{\circ} \mathrm{C}$ in a humidified $5 \% \mathrm{CO}_{2}$ atmosphere. Cells in the exponential growth phase were plated, and were cultured at $37^{\circ} \mathrm{C}$ in $5 \% \mathrm{CO}_{2}$ for $24 \mathrm{~h}$. Cells in the normoxia (N) group were incubated at $37^{\circ} \mathrm{C}$ with $95 \%$ atmospheric air $/ 5 \% \mathrm{CO}_{2}$ at $6 \mathrm{l} / \mathrm{min}$ for $4 \mathrm{~h}$. Cells in the hypoxia $(\mathrm{H})$ group were incubated at $37^{\circ} \mathrm{C}$ in $94 \% \mathrm{~N}_{2} / 5 \% \mathrm{CO}_{2} / 1 \% \mathrm{O}_{2}$ at $6 \mathrm{l} / \mathrm{min}$ for $4 \mathrm{~h}$. Cells in the hypoxic + DEX (HD) group were treated with $1 \mathrm{nM}$ DEX (Aibeining ${ }^{\circledR}$; Jiangsu Hengrui Medicine Co., Ltd.) and incubated at $37^{\circ} \mathrm{C}$ in $94 \% \mathrm{~N}_{2} / 5 \% \mathrm{CO}_{2} / 1 \% \mathrm{O}_{2}$ at $6 \mathrm{l} / \mathrm{min}$ for $4 \mathrm{~h}$. Cells in the hypoxia + DEX + atipamezole (HDA) group were treated with $1 \mathrm{nM}$ DEX, $10 \mathrm{nM}$ atipamezole (Sigma-Aldrich; Merck $\mathrm{KGaA}$ ), at $37^{\circ} \mathrm{C}$ in $94 \% \mathrm{~N}_{2} / 5 \% \mathrm{CO}_{2} / 1 \% \mathrm{O}_{2}$ at $6 \mathrm{l} / \mathrm{min}$ for $4 \mathrm{~h}$. The duration of DEX treatment chosen was $4 \mathrm{~h}$ in the present study to model surgeries, which based on observations at Affiliated FoShan Hospital of Sun Yat-Sen University, China typically last 2-6 h.

MTT assay. MTT assay was used to examine cell viability. Cells were incubated at $37^{\circ} \mathrm{C}$ in 96 -well plates $\left(1 \times 10^{4}\right.$ cells/well $)$ overnight. Following treatment, the cells were further cultured at $37^{\circ} \mathrm{C}$ in DMEM supplemented with $10 \% \mathrm{FBS}$ for $48 \mathrm{~h}$ prior to the addition of MTT to each well. Thereafter, MTT was added to each well and mixed. The cells were then incubated for an additional $4 \mathrm{~h}$. The media was removed and DMSO was added to each well to fully dissolve the blue crystals. Absorbance was then measured at $570 \mathrm{~nm}$ (optical density 570) using a spectrophotometer.

Transwell assay. Transwell assays were used to evaluate the invasion and migration ability of cells. The upper chambers of transwell plates (24-well; Costar; Corning, Inc.) were coated with $100 \mu \mathrm{l}$ of $0.2 \mathrm{mg} / \mathrm{ml}$ Matrigel (Corning, Inc.) and left to dry overnight at room temperature. Following treatment, A549 cells and HCT116 cells were seeded in the upper chamber (1x10 ${ }^{5}$ cells/well) of these Matrigel-coated 24-well Transwell plate for $24 \mathrm{~h}$. DMEM containing $10 \%$ FBS was loaded into the lower well $(600 \mu \mathrm{l} /$ well) and serum-free medium was loaded into the upper chamber. The cells were cultured at $37^{\circ} \mathrm{C}$ in $5 \% \mathrm{CO}_{2}$ for $24 \mathrm{~h}$. Cells that did not pass through the polycarbonate membrane at the bottom of the chamber were scraped gently with a cotton swab. The membrane was removed and fixed with methanol for $15 \mathrm{~min}$ and stained with $0.5 \%$ crystal violet at room temperature for $20 \mathrm{~min}$. The number of invasive cells was counted from five fields of vision that were selected randomly using an inverted light microscope (MSHOT/MC30 Digital imaging system; Guangzhou Micro-shot Technology Co., Ltd.) under x200 magnification. The migration ability of cells was determined following the same approach but without the Matrigel coating.

Western blotting. Cells were washed with PBS, lysed on ice for $30 \mathrm{~min}$ with lysis buffer [containing $20 \mathrm{mM}$ Tris- $\mathrm{HCl} \mathrm{pH} 7.5$, $150 \mathrm{mM} \mathrm{NaCl}, 1 \mathrm{mM}$ EDTA, $1 \mathrm{mM}$ EGTA, $1 \%$ (v/v) Triton $\mathrm{X}-100,0.5 \%$ (v/v) Nonidet P40, $2.5 \mathrm{mM}$ sodium pyrophosphate, $1 \mathrm{mM}$ sodium orthovanadate, $50 \mathrm{mM}$ sodium fluoride and $1 \mathrm{x}$ protease inhibitor cocktail] and then centrifuged at 18,894 x g for $15 \mathrm{~min}$ at $4^{\circ} \mathrm{C}$. The supernatants were collected and assessed for protein concentration using a BCA assay. Proteins (50 $\mu \mathrm{g}$ per sample) were separated on $12 \%$ SDS-PAGE gels, and then electrophoretically transferred onto a polyvinylidene difluoride membrane (EMD Millipore). Membranes were blocked with 5\% BSA (Shanghai Rong Biological Technology Co., Ltd.) and with TBST (0.05\% Tween 20$)$ at $4^{\circ} \mathrm{C}$ for $1 \mathrm{~h}$. The membrane was then incubated overnight at $4^{\circ} \mathrm{C}$ with anti-survivin antibodies [Santa Cruz Biotechnology, Inc.; mouse monoclonal antibody (mAb); cat. no. sc-17779; dilution 1:500], anti-HIF-1 $\alpha$ antibody (Santa Cruz Biotechnology, Inc.; mouse mAb; cat. no. sc-13515; dilution 1:500), and anti-GAPDH antibody (Santa Cruz Biotechnology, Inc.; mouse mAb; cat. no. sc-365062; dilution 1:1,000), followed by incubation at $4^{\circ} \mathrm{C}$ with fluorescence-conjugated secondary antibodies (Santa Cruz Biotechnology, Inc.; normal anti-mouse IgG Alexa Fluor ${ }^{\circledR}$ 680; cat. no. sc-516610; dilution 1:400) for $2 \mathrm{~h}$. The protein signals were analyzed using an Odyssey IR scanner (LI-COR Biosciences), and signal intensities were quantified using NIH ImageJ software (v.16.0; National Institutes of Health). Expression levels of each protein were measured relative to GAPDH.

Reverse transcription-quantitative RT-qPCR. For the detection of the levels of matrix metalloproteinase (MMP)-2 and MMP-9 expression in the two cells, RT-qPCR was performed. Cell mRNA was isolated with TRIzol ${ }^{\circledR}$ reagent (Invitrogen; Thermo Fisher Scientific, Inc.), and cDNA was synthesized with the M-MLV Reverse Transcription kit (Promega Corporation). The tube was heated at $65^{\circ} \mathrm{C}$ for $10 \mathrm{~min}$. Transcriptor reverse transcriptase reaction buffer $(4 \mu \mathrm{l})$, RNA inhibitor $(0.5 \mu 1)$, deoxynucleotide mix (10 mM; $2 \mu \mathrm{l})$, and Transcriptor reverse transcriptase $(0.5 \mu \mathrm{l})$ were added. The reagents were mixed in the tube carefully. Tubes were put in the PCR machine at 

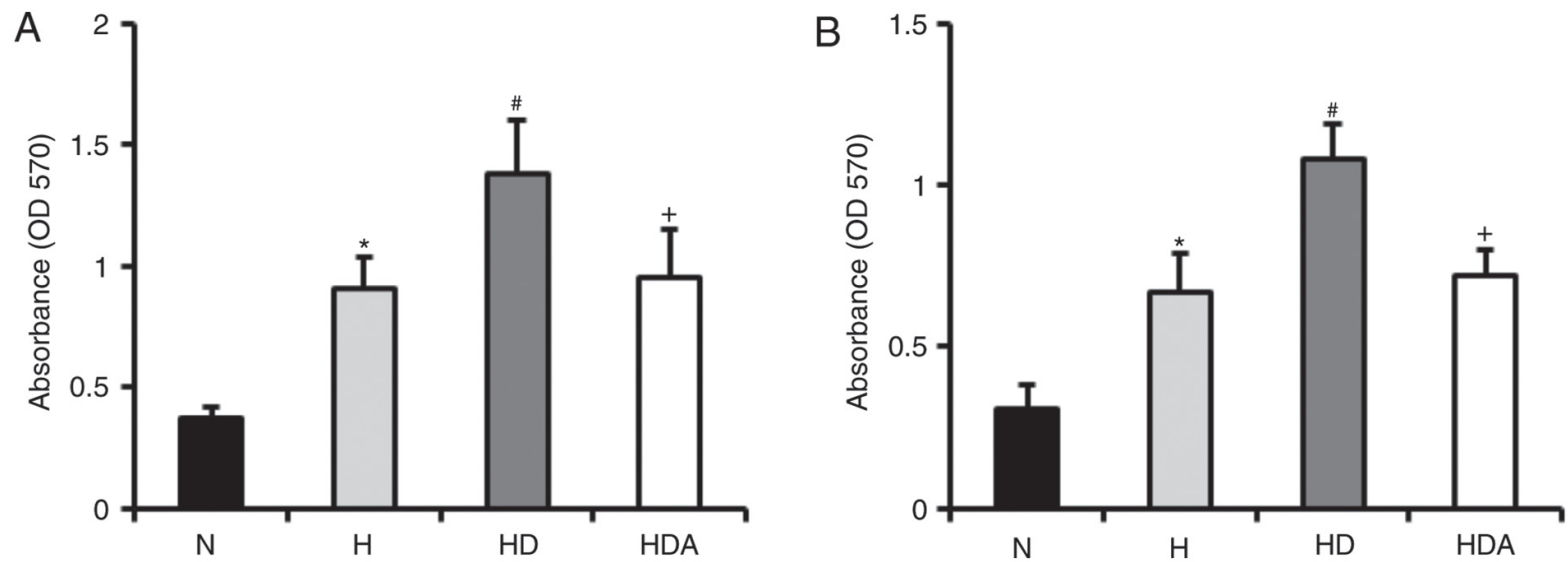

Figure 1. Dexmedetomidine promotes the hypoxia-induced viability of cancer cell lines. (A) Viability of A549 cells in group N, group H, group HD and group HDA. (B) The viability of HCT116 cells in group N, group H, group HD and group HDA. The proliferation rate of the cells was determined by MTT assay. ${ }^{*} \mathrm{P}<0.05$ vs. $\mathrm{N} ;{ }^{*} \mathrm{P}<0.05$ vs. $\mathrm{H} ;{ }^{+} \mathrm{P}<0.05$ vs. $\mathrm{HD} ; \mathrm{n}=6$ in each group. $\mathrm{H}$, hypoxia; HD, hypoxia + dexmedetomidine; HDA, hypoxia + dexmedetomidine + atipamezole; N, normoxia; OD, optical density.

$25^{\circ} \mathrm{C}$ for $10 \mathrm{~min}$ followed by $60 \mathrm{~min}$ at $50^{\circ} \mathrm{C}$, then $85^{\circ} \mathrm{C}$ for 5 min. qPCR was performed using IQ SYBR Green Supermix reagent (Bio-Rad Laboratories, Inc.) with a Bio-Rad real-time PCR machine, according to the manufacturer's instructions. Denaturation was performed at $95^{\circ} \mathrm{C}$ for $20 \mathrm{sec}$, followed by 38 cycles of $95^{\circ} \mathrm{C}$ for $5 \mathrm{sec}, 50^{\circ} \mathrm{C}$ for $45 \mathrm{sec}$ and $72^{\circ} \mathrm{C}$ for $30 \mathrm{sec}$. The data were analyzed using the $2^{-\Delta \Delta \mathrm{Cq}}$ method (22). The expression levels of the target genes were normalized to the GAPDH level in each sample. The primer sequences were as follows: MMP-2, forward 5'-GCAGCCCATGAGTTCGGC CAT-3' and reverse 5'-AGCATCAGGGGAGGGCCCATA-3'; MMP-9, forward 5'-GGAGACGGCAAACCCTGCGT-3' and reverse 5'-TGACGTCGGCTCGAGTAGGACA-3'; and GAPDH, forward 5'-AGGTCGGTGTGAACGGATTTG-3' and reverse 5'-TGTAGACCATGTAGTTGAGGTCA-3'.

Statistical analysis. Data analysis was performed using SPSS for Windows (v.16.0; SPSS Inc.). Data are expressed as mean \pm standard error of the mean. Differences between the means of the groups were assessed by one-way ANOVA followed by least significant difference tests (in cases of equal variance) or Dunnett's test (when there was heterogeneity in the variance) for post hoc comparisons. $\mathrm{P}<0.05$ was considered to indicate a statistically significant difference.

\section{Results}

DEX promotes hypoxia-induced proliferation. To examine whether DEX promotes hypoxia-induced proliferation of A549 cells and HCT116 cells, cells were treated with DEX and hypoxia for $4 \mathrm{~h}$ (Fig. 1). The results revealed that hypoxia-treated cells developed a significant elevation of proliferative rate compared with cells treated with normoxia $(\mathrm{P}<0.05)$. The proliferation rate of DEX-treated cells following hypoxia insult was markedly higher than that of cells treated with hypoxia alone $(\mathrm{P}<0.05)$. These data indicated that DEX promoted the hypoxia-induced proliferation of the two cancer cell lines. Furthermore, atipamezole almost fully abolished the effects of DEX on the proliferation of the cancer lines following hypoxia-induced proliferation.
DEX increases the protein levels of survivin in cells following hypoxia treatment. Whether DEX was able to increase the expression of survivin was subsequently investigated. Through western blotting, it was demonstrated that survivin was markedly induced in A549 cells and HCT116 cells in response to hypoxia treatment, compared with normoxia treatment ( $\mathrm{P}<0.05$; Fig. 2). Moreover, DEX further upregulated the protein levels of survivin in the two cancer cell lines after hypoxia ( $\mathrm{P}<0.05$ compared with the $\mathrm{H}$ group). The effects of DEX on the hypoxia-induced expression of survivin were almost fully abrogated by atipamezole treatment $(\mathrm{P}<0.05)$. These findings suggested that DEX may increase the hypoxia-induced proliferation of the two cancer cell lines by regulating survivin expression, which may be associated with an $\alpha_{2}$ adrenoceptor mediated mechanism of action.

DEX enhances hypoxia-induced invasion ability. It has been reported that DEX contributes to the invasion of breast cancer cells under normal condition $(14,15)$. Based on this information, it was hypothesized that DEX may also enhance the hypoxia-induced invasion of A549 cells and HCT116 cells. Through Matrigel assays, it was revealed that the invasive number of cells from the two cancer cell lines was increased significantly after hypoxia treatment $(\mathrm{P}<0.05$; Fig. 3$)$. The invasive cell number in the HD group was elevated substantially as compared with the $\mathrm{H}$ group for both cancer cell lines $(\mathrm{P}<0.05)$. These data indicated that DEX exacerbated the hypoxia-induced invasive potential of the two cancer cell lines. The invasive cell number in the HDA group was reduced significantly as compared with the HD group $(\mathrm{P}<0.05)$. These results suggested that atipamezole reversed the effects of DEX on the hypoxia-induced invasion of the two cancer cell lines.

DEX aggravates hypoxia-induced migration ability. Subsequently, the present study assessed whether DEX increases the hypoxia-induced migration of A549 cells and HCT116 cells. Using Transwell assays, the findings showed that the number of migrated cells from the two cell cancer lines was elevated significantly after hypoxia treatment (Fig. 4). In comparison, treatment with DEX further significantly 

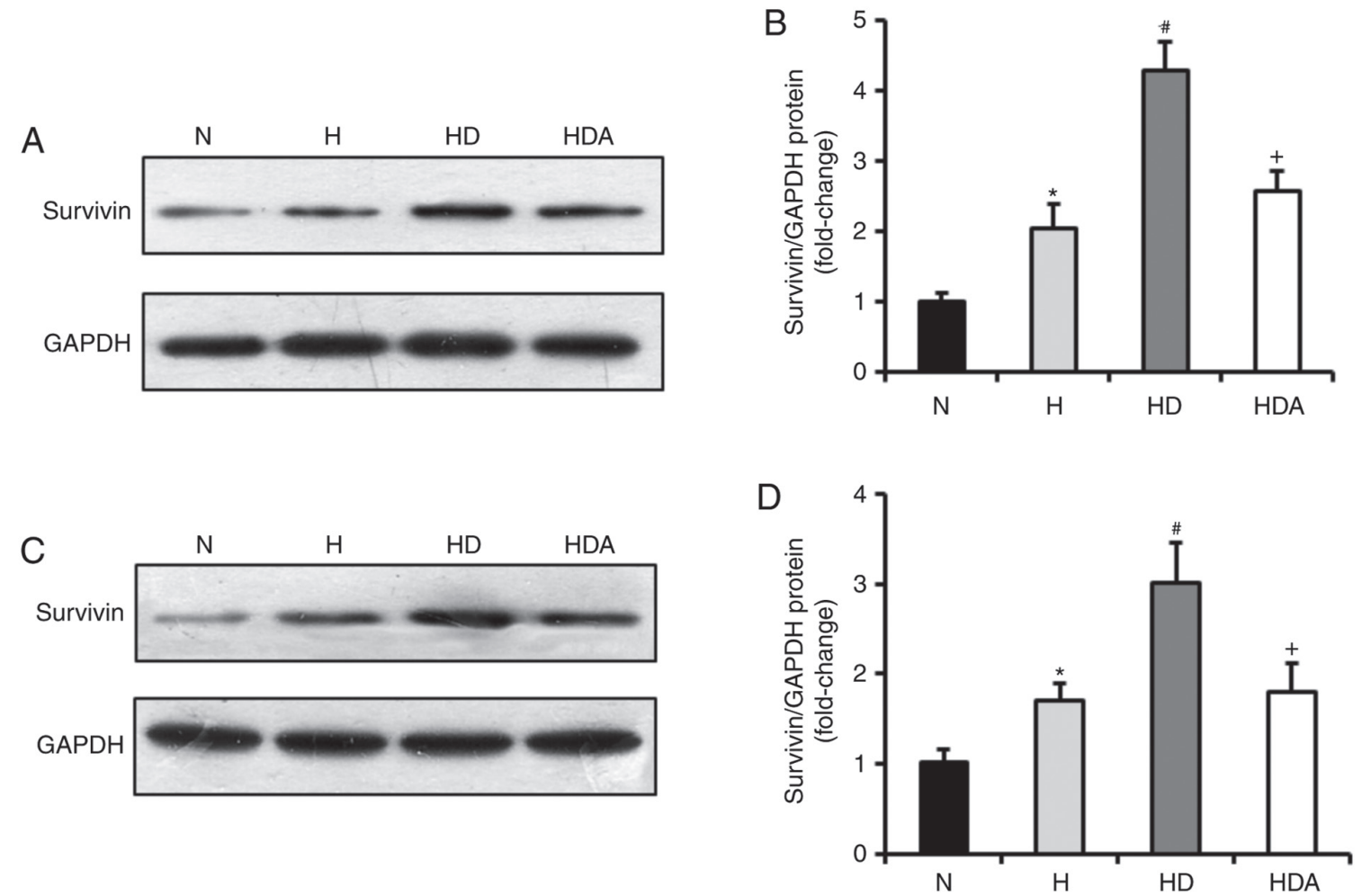

Figure 2. Dexmedetomidine increases the protein levels of survivin in cancer cells following hypoxia insult. (A) Representative western blotting showing the levels of survivin protein expression in the A549 cells. (B) Quantitative analysis of survivin protein expression in the A549 cells. (C) Representative western blotting showing the levels of survivin protein expression in the HCT116 cells. (D) Quantitative analysis of survivin protein expression in the HCT116 cells. The survivin protein expression of the two cells was detected by western blotting and all values are normalized against the $\mathrm{N}$ group. ${ }^{*} \mathrm{P}<0.05$ vs. $\mathrm{N} ;{ }^{*} \mathrm{P}<0.05$ vs. $\mathrm{H} ;{ }^{+} \mathrm{P}<0.05$ vs. HD; $\mathrm{n}=6$ in each group. $\mathrm{H}$, hypoxia; HD, hypoxia + dexmedetomidine; HDA, hypoxia + dexmedetomidine + atipamezole; $\mathrm{N}$, normoxia.

increased the number of migratory cells $(\mathrm{P}<0.05)$. These results suggested that DEX aggravated hypoxia-induced migratory ability. The migratory cell number in the HDA group decreased substantially as compared with the HD group $(\mathrm{P}<0.05)$. These data indicated that atipamezole abolished the effect of DEX on the hypoxia-induced migration of the two cancer cell lines.

DEX upregulates the MRNA levels of MMP-2 and MMP-9 in cancer cells in response to hypoxia. MMP-2 and MMP-9 both have critical roles in the metastasis of cancer cells (23). RT-qPCR was used to investigate whether DEX increased the mRNA levels of MMP-2 and MMP-9 (Fig. 5). It was found that hypoxia treatment significantly upregulated the mRNA levels of both MMP-2 and MMP-9 in the two cancer cell lines $(\mathrm{P}<0.05)$. The mRNA levels of MMP-2 and MMP-9 were increased significantly in the HD group compared with the $\mathrm{H}$ group $(\mathrm{P}<0.05)$. Compared with the HD group, the mRNA levels of MMP-2 and MMP-9 in group HDA were significantly elevated $(\mathrm{P}<0.05)$. Furthermore, atipamezole reversed the effects of DEX on the hypoxia-induced mRNA expression of MMP-2 and MMP-9 in the two cancer cell lines (Fig. 5). These results indicated that DEX may enhance the hypoxia-induced metastatic potential of the two cancer cell lines by regulating MMP-2 and MMP-9 expression, which may be dependent on the $\alpha_{2}$ adrenoceptor.

DEX drives upregulation of HIF-1 $\alpha$ protein in cells following hypoxic stress. It has been documented that DEX has a protective influence on organs by upregulating HIF-1 $\alpha$ (24). Therefore, the present study examined whether DEX affected the protein expression of HIF-1 $\alpha$ in the two cancer cell lines (Fig. 6). The results of the western blotting showed that the HIF-1 $\alpha$ protein levels of the two cells were elevated markedly in response to hypoxia $(\mathrm{P}<0.05)$. Cells treated with DEX and hypoxia displayed a significant elevation of HIF- $1 \alpha$ protein compared with cells exposed to hypoxia alone $(\mathrm{P}<0.05)$. These data suggested that the effects of DEX on hypoxia-induced growth and metastasis of the cancer cells may be related to upregulation of HIF-1 $\alpha$ signaling. Furthermore, treatment with atipamezole abolished the effects of DEX on hypoxia-induced expression of HIF-1 $\alpha(\mathrm{P}<0.05)$, suggesting the effect of DEX on HIF-1 $\alpha$ expression may be mediated by $\alpha_{2}$ adrenoceptor signaling.

DEX enhances the progression of cancer cells under normoxic conditions. The effects of DEX on the biological functions of A549 cells and HCT116 cells under normoxic condition were also examined. The results demonstrated that DEX may enhance proliferation and metastasis of these two cancer cells treated with normoxia (data not shown). These results suggested that DEX promotes cancer cell progression under normoxic condition.

\section{Discussion}

The perioperative period is a critical time of metastatic vulnerability as dissemination of tumor cells often occurs 
A

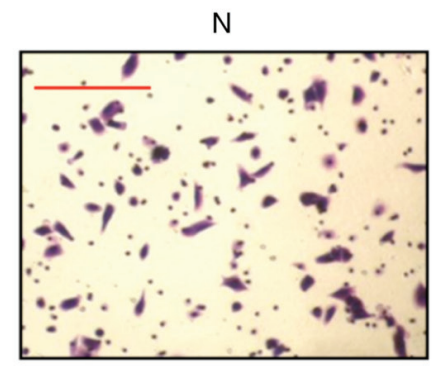

HD

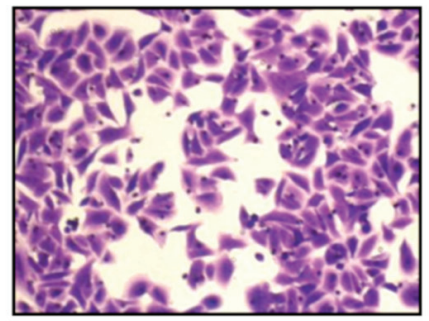

C

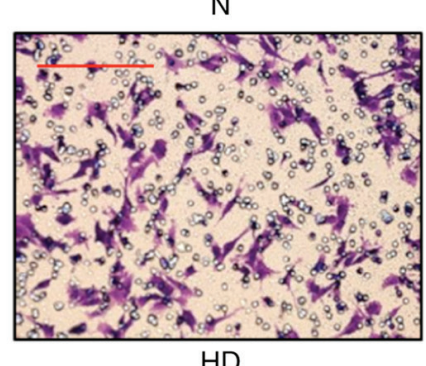

$\mathrm{HD}$

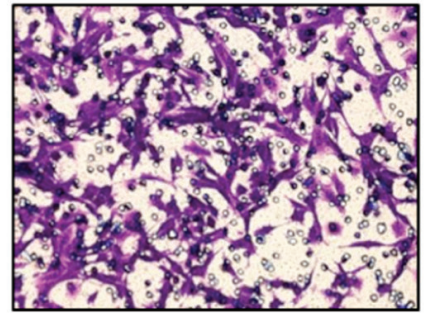

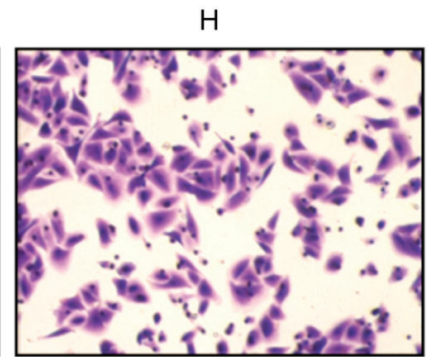

HDA

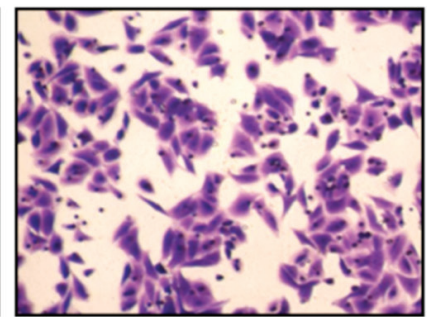

$\mathrm{H}$

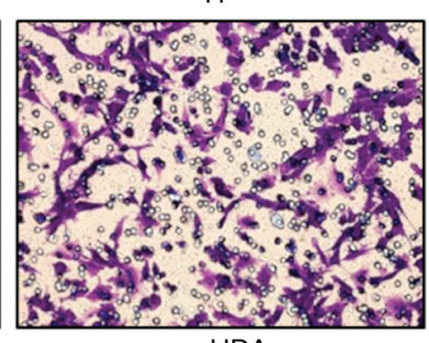

HDA

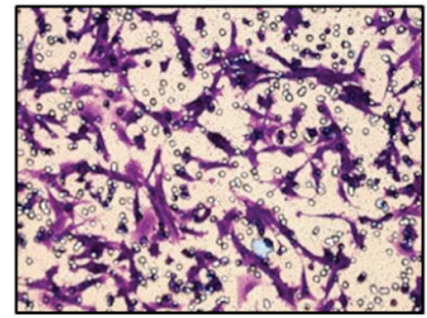

B

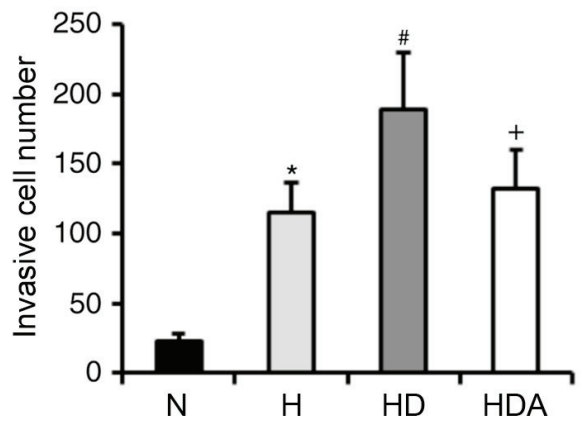

D

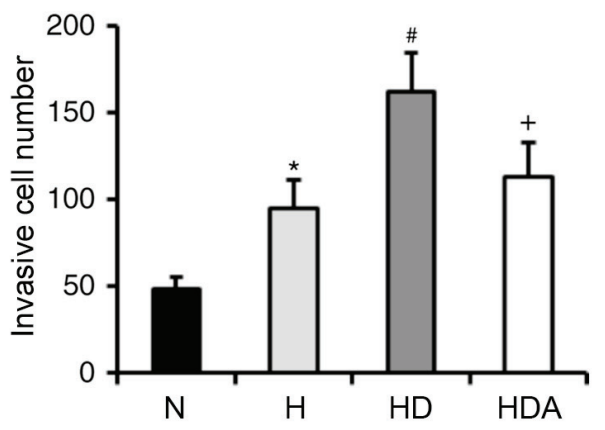

Figure 3. Dexmedetomidine enhances the hypoxia-induced invasion ability of cancer cells. (A) Representative images showing the invasion of the A549 cells. (B) Quantitative analysis of invasive cell number of A549 cells. (C) Representative images showing the invasion of the HCT116 cells. (D) Quantitative analysis of invasive cell number of HCT116 cells. The invasion ability of the two cells were detected by Matrigel assays. ${ }^{*} \mathrm{P}<0.05$ vs. $\mathrm{N} ;{ }^{*} \mathrm{P}<0.05 \mathrm{vs}$. $\mathrm{H}$; ${ }^{+} \mathrm{P}<0.05$ vs. $\mathrm{HD}$; $\mathrm{n}=6$ in each group; scale bars represent $50 \mu \mathrm{m}$. H, hypoxia; HD, hypoxia + dexmedetomidine; HAD, hypoxia + dexmedetomidine + atipamezole; N, normoxia.

during surgery (25). Evidence shows that anesthetic agents have an important impact on the biological behaviors of tumor cells and may influence the recurrence or the progression of cancer $(26,27)$. Thus, the choice of anesthetic drugs during the perioperative period of cancer surgery should be considered seriously. Hypoxia is one of the most important features of solid tumors, and has been shown to contribute to the proliferation and metastasis of cancer cells (28). Unfortunately, hypoxia is a common complication during the perioperative period. DEX is increasingly used as an adjunct to anesthesia. Therefore, a better understanding of the effects of DEX on the hypoxia-induced progression of cancer cells is urgently needed.

In the present study, the following points were demonstrated: i) DEX may enhance the hypoxia-induced growth and metastatic potential of A549 cells and HCT116 cells; ii) DEX increased the protein expression of survivin for both of the two cancer cell lines in response to hypoxic stress; iii) DEX further promoted the hypoxia-induced invasive and migratory ability of the two cancer cell lines; iv) DEX promoted the upregulation of MMP-2, MMP-9 and HIF-1 $\alpha$ mRNA expression of the two cancer cell lines after hypoxia; and v) the effects of DEX on hypoxia-induced progression of cancer cells may be brought about in an $\alpha_{2}$ adrenoreceptor-dependent manner. These data suggested that DEX enhanced the hypoxia-induced progression of lung cancer cells and colorectal cancer cells via the regulation of HIF-1 $\alpha$ signaling, which may be functioning in an $\alpha_{2}$ adrenoceptor-dependent pathway.

Survivin is a member of the inhibitor of apoptosis protein family, which is expressed in a wide variety of human tumors. Survivin orchestrates several important mechanisms to promote the proliferation of cancer cells, including anti-apoptotic activity and regulation of the cell cycle (29). Overexpression of survivin in cancer cells is associated with massive proliferation of cancer cells, resulting in a poor prognosis (30). In this present study, it was demonstrated that the expression of survivin in the two cancer cell lines was substantially elevated after hypoxic treatment. Furthermore, 
A

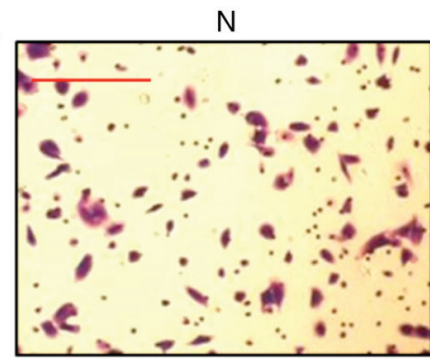

HD

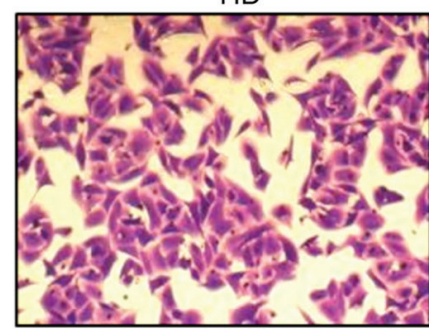

C

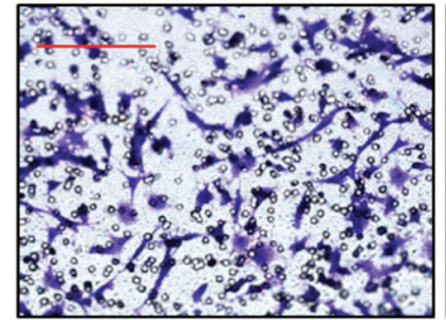

HD

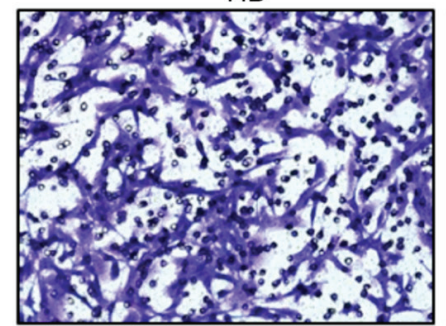

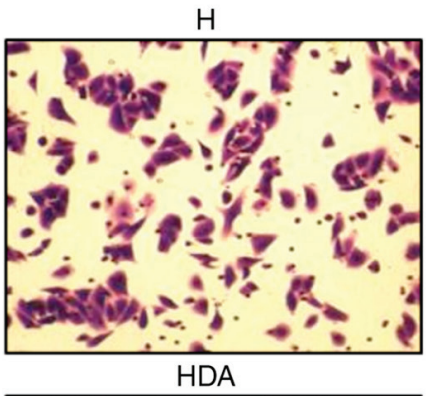

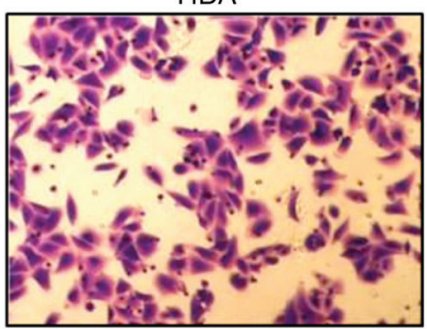

$\mathrm{H}$

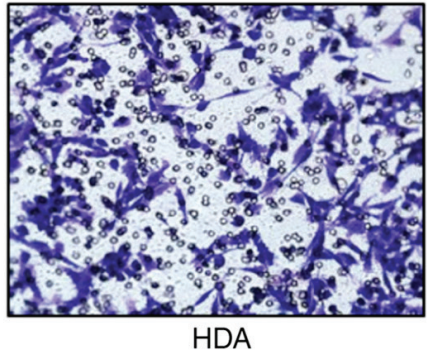

HDA

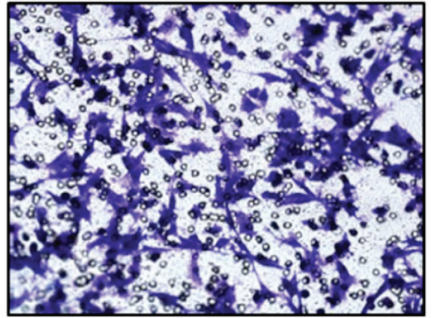

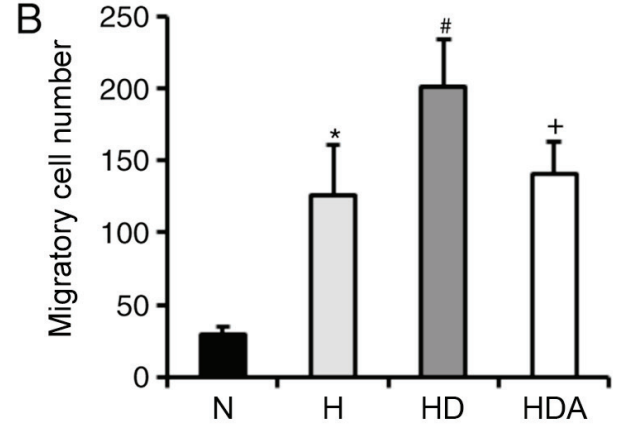

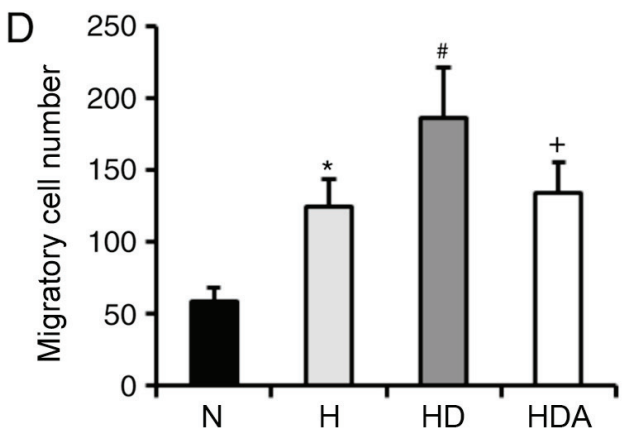

Figure 4. Dexmedetomidine aggravates the hypoxia-induced migratory ability of cancer cells. (A) Representative images showing the migration of the A549 cells. (B) Quantitative analysis of migratory cell number of A549 cells. (C) Representative images showing the migration of the HCT116 cells. (D) Quantitative analysis of migratory cell number of HCT116 cells. The migratory ability of the two cells was detected by Transwell assay. ${ }^{*} \mathrm{P}<0.05$ vs. $\mathrm{N}$; ${ }^{\#} \mathrm{P}<0.05$ vs. $\mathrm{H}$; ${ }^{+} \mathrm{P}<0.05$ vs. HD; $\mathrm{n}=6$ in each group; scale bars represent $50 \mu \mathrm{m}$. H, hypoxia; HD, hypoxia + dexmedetomidine; HDA, hypoxia + dexmedetomidine + atipamezole; N, normoxia;

treatment with DEX increased the protein levels of survivin in A549 cells and HCT cells in response to hypoxic stress. These results indicated that DEX may contribute to hypoxia-induced proliferation of cancer cells by regulating the expression of survivin.

MMP-2 and MMP-9 are both zinc-dependent proteolytic enzymes that are capable of cleaving extracellular matrix and basement membrane components. The two enzymes directly facilitate tumor invasion and migration, and play a prominent role in metastasis (23). Overexpression of MMP-2 and MMP-9 is consistently related to cancer metastasis and poorer prognosis (23). In the present study, it was observed that the mRNA expression of both MMP-2 and MMP-9 was increased significantly in the two cancer cell lines following hypoxia. Moreover, DEX treatment promoted the hypoxia-induced raised expression of MMP-2 and MMP-9. These data suggested that DEX may promote the invasion and migration of cancer cells induced by hypoxia, by upregulating MMP-2 and MMP-9.

HIF-1 is composed of HIF-1 $\alpha$ and HIF-1 $\beta$. As an oxygen sensor in hypoxic microenvironments, HIF-1 $\alpha$ regulates cancer cell metabolism, proliferation, apoptosis and metastasis (31). Under hypoxic conditions, HIF-1 $\alpha$ binds to HIF-1 $\beta$ to form the HIF-1 transcription complex that activates the transcription of many target genes, including survivin and MMPs (32-35). In the present study, the findings showed that hypoxia treatment upregulated the HIF-1 $\alpha$ levels of the two cancer cell lines. Recently, a study reported that DEX protects against lung ischemia-reperfusion injury via upregulation of HIF-1 $\alpha$ (24). The findings of this present study also showed that DEX may drive the upregulation of HIF-1 $\alpha$ expression in cancer cells following hypoxic insult. These data indicated that DEX may enhance hypoxia-induced cancer cell progression by modulating the HIF-1 $\alpha$ signaling pathway. 
A

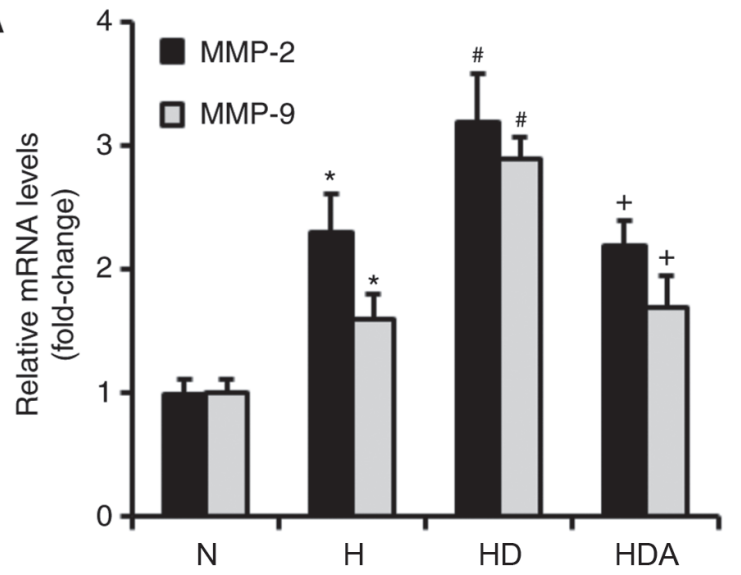

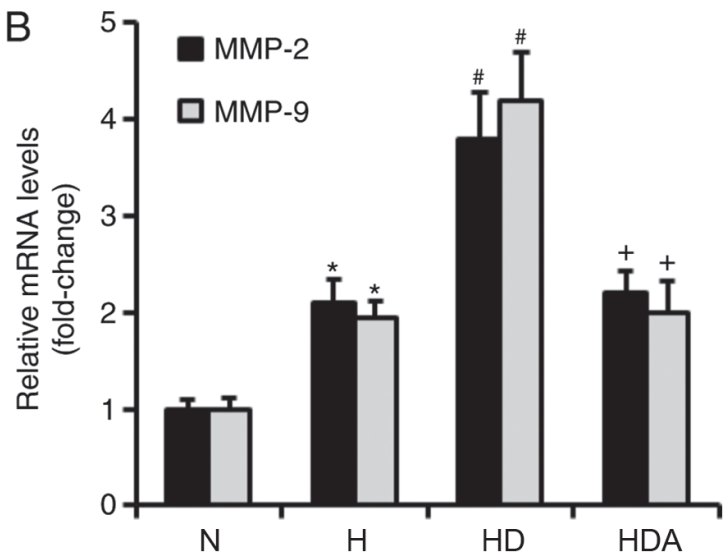

Figure 5. Dexmedetomidine upregulates the mRNA levels of MMP-2 and MMP-9 in cancer cells in response to hypoxia treatment. (A) Quantitative analysis of MMP-2 and MMP-9 mRNA levels in the A549 cells. (B) Quantitative analysis of MMP-2 and MMP-9 mRNA levels in the HCT116 cells. The MMP-2 and MMP-9 mRNA expression levels of the two cells were evaluated by reverse transcription-quantitative $\mathrm{PCR}$. ${ }^{*} \mathrm{P}<0.05$ vs. $\mathrm{N} ;{ }^{*} \mathrm{P}<0.05$ vs. $\mathrm{H} ;{ }^{+} \mathrm{P}<0.05$ vs. HD; $\mathrm{n}=6$ in each group; all values are normalized against the $\mathrm{N}$ group. $\mathrm{H}$, hypoxia; $\mathrm{HD}$, hypoxia + dexmedetomidine; HDA, hypoxia + dexmedetomidine + atipamezole; MMP, matrix metalloproteinase; $\mathrm{N}$, normoxia.

A
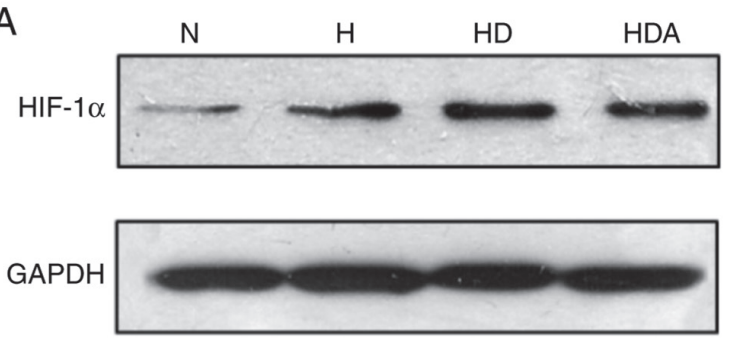

C
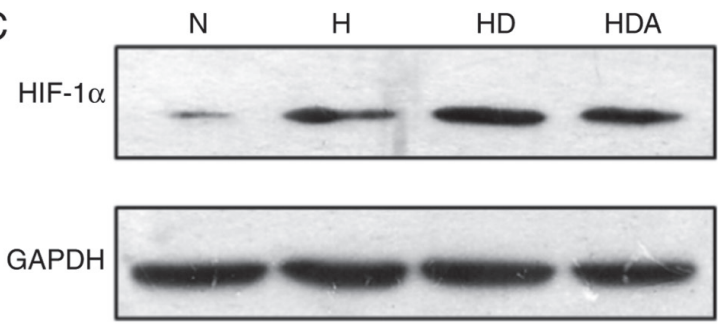

B
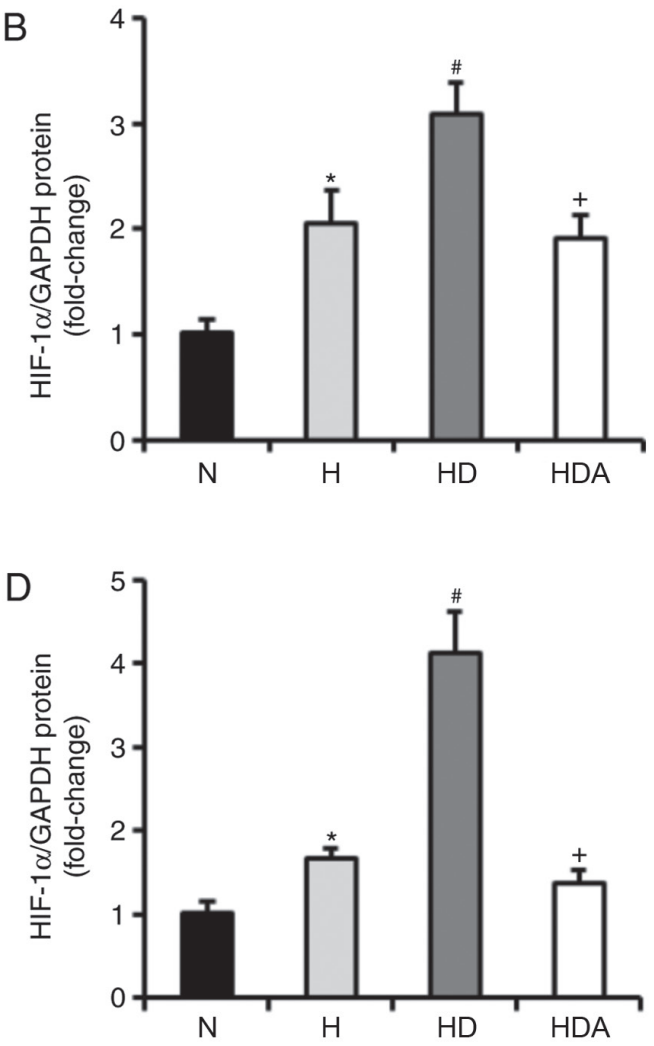

Figure 6. Dexmedetomidine increases the protein levels of HIF-1 $\alpha$ in cancer cells following hypoxia treatment. (A) Representative western blots showing the levels of HIF-1 $\alpha$ protein expression in the A549 cells. (B) Quantitative analysis of HIF-1 $\alpha$ protein expression in the A549 cells. (C) Representative western blotting showing the levels of HIF-1 $\alpha$ protein expression in the HCT116 cells. (D) Quantitative analysis of HIF-1 $\alpha$ protein expression in the HCT116 cells. ${ }^{*} \mathrm{P}<0.05$ vs. $\mathrm{N} ;{ }^{*} \mathrm{P}<0.05$ vs. $\mathrm{H} ;{ }^{+} \mathrm{P}<0.05$ vs. HD; $\mathrm{n}=6$ in each group; all values are normalized against the $\mathrm{N}$ group. $\mathrm{H}$, hypoxia; HD, hypoxia + dexmedetomidine; HDA, hypoxia + dexmedetomidine + atipamezole; N, normoxia.

It is reported that the organ-protective effects of DEX are regulated by $\alpha_{2}$ adrenoceptors $(36,37)$. This present study investigated whether $\alpha_{2}$ adrenoceptors play a role in the effect of DEX on the progression of the two cancer cell lines. It was demonstrated that the effect of DEX on the hypoxia-induced proliferation and metastatic ability of cancer cells may be abolished by atipamezole. In addition, the effects of DEX on the hypoxia-induced expression of survivin, MMP-2, MMP-9 and HIF-1 $\alpha$ were removed by atipamezole. The present data suggested that the effect of DEX on hypoxia-induced cancer cell progression may occur in an $\alpha_{2}$ adrenoceptor mediated manner.

This present study also investigated the effects of DEX on the biological function of A549 cells and HCT cells under 
normoxic conditions. It was revealed that DEX may enhance proliferation and the metastasis of these two cancer cell lines under normoxic conditions (data not shown), suggesting that DEX promotes cancer cell progression under normoxic conditions.

In conclusion, dexmedetomidine enhances the hypoxia-induced progression of lung cancer cells and colorectal cancer cells by regulating HIF-1 $\alpha$ signaling, which may function though the $\alpha_{2}$ adrenoceptor pathway.

\section{Acknowledgements}

Not applicable.

\section{Funding}

This study was supported by Guangdong Province Science and Technology Planning Project, Guangdong, China (grant no. 2014A020212467).

\section{Availability of data and materials}

The datasets used and/or analyzed during the present study are available from the corresponding author on reasonable request.

\section{Authors' contributions}

HYC performed the experiments and revised this manuscript. JYZ performed the western blotting and data analysis. GHL performed the Transwell assays and data analysis. GCT and XHL were responsible for proliferation evaluation, western blotting and RT-qPCR. HL and QH conceived and designed this investigation. All authors read and approved the final version of the manuscript.

\section{Ethics approval and consent to participate}

Not applicable.

\section{Patient consent for publication}

Not applicable.

\section{Competing interests}

The authors declare that they have no competing interests.

\section{References}

1. Hopewood P and Milroy MJ: Milroy MJ (Ed) Cancer Statistics: Global and National. In: Quality Cancer Care. Springer, New York, NY, USA, pp 29-35, 2018

2. Bray F, Ferlay J, Soerjomataram I, Siegel RL, Torre LA and Jemal A: Global cancer statistics 2018: GLOBOCAN estimates of incidence and mortality worldwide for 36 cancers in 185 countries. CA Cancer J Clin 68: 394-424, 2018.

3. Hiller JG, Perry NJ, Poulogiannis G, Riedel B and Sloan EK: Perioperative events influence cancer recurrence risk after surgery. Nat Rev Clin Oncol 15: 205-218, 2018.

4. Olcina MM, Kim RK, Melemenidis S, Graves EE and Giaccia AJ: The tumour microenvironment links complement system dysregulation and hypoxic signalling. Br J Radiol 15: 20180069, 2018 (Epub ahead of print).
5. Wigerup C, Påhlman S and Bexell D: Therapeutic targeting of hypoxia and hypoxia-inducible factors in cancer. Pharmacol Ther 164: 152-169, 2016.

6. Gupta K, Prasad A, Nagappa M, Wong J, Abrahamyan L and Chung FF: Risk factors for opioid-induced respiratory depression and failure to rescue: A review. Curr Opin Anaesthesiol 31: 110-119, 2018.

7. Campos JH and Feider A: Hypoxia during one-lung ventilation-a review and update. J Cardiothorac Vasc Anesth 32: 2330-2338, 2018.

8. Soltanizadeh S, Degett TH and Gogenur I: Outcomes of cancer surgery after inhalational and intravenous anesthesia: A systematic review. J Clin Anesth 42: 19-25, 2017.

9. Cassinello F, Prieto I, del Olmo M, Rivas S and Strichartz GR: Cancer surgery: How may anesthesia influence outcome? J Clin Anesth 27: 262-272, 2015 .

10. Wu GJ, Chen JT, Tsai HC, Chen TL, Liu SH and Chen RM: Protection of dexmedetomidine against ischemia/reperfusion-induced apoptotic insults to neuronal cells occurs via an intrinsic mitochondria-dependent pathway. J Cell Biochem 118: 2635-2644, 2017

11. Wang SL, Duan L, Xia B, Liu Z, Wang Y and Wang GM: Dexmedetomidine preconditioning plays a neuroprotective role and suppresses TLR4/NF-kB pathways model of cerebral ischemia reperfusion. Biomed Pharmacother 93: 1337-1342, 2017.

12. Cui J,Zhao H, Wang C, Sun JJ,Lu K and Ma D: Dexmedetomidine attenuates oxidative stress induced lung alveolar epithelial cell apoptosis in vitro. Oxid Med Cell Longev 2015: 358396, 2015.

13. Cho JS, Shim JK, Soh S, Kim MK and Kwak YL: Perioperative dexmedetomidine reduces the incidence and severity of acute kidney injury following valvular heart surgery. Kidney Int 89: 693-700, 2016.

14. Szpunar MJ, Burke KA, Dawes RP, Brown EB and Madden KS: The antidepressant desipramine and alpha2-adrenergic receptor activation promote breast tumor progression in association with altered collagen structure. Cancer Prev Res (Phila) 6: 1262-1272, 2013.

15. Bruzzone A, Pinero CP, Castillo LF, Sarappa MG, Rojas P, Lanari C and Luthy IA: Alpha2-adrenoceptor action on cell proliferation and mammary tumour growth in mice. Br J Pharmacol 155: 494-504, 2008.

16. Castillo LF, Rivero EM, Goffin V and Luthy IA: Alpha2-adrenoceptor agonists trigger prolactin signaling in breast cancer cells. Cell Signal 34: 76-85, 2017.

17. Deng F, Ouyang M, Wang X, Yao X, Chen Y, Tao T, Sun X, Xu L, Tang J and Zhao L: Differential role of intravenous anesthetics in colorectal cancer progression: Implications for clinical application. Oncotarget 7: 77087-77095, 2016.

18. Virtanen R: Pharmacological profiles of medetomidine and its antagonists, atipamezole. Acta Vet Scand Suppl 85: 29-37, 1989.

19. Liang H, Yang CX, Zhang B, Wang HB, Liu HZ, Lai XH, Liao MJ and Zhang T: Sevoflurane suppresses hypoxia-induced growth and metastasis of lung cancer cells via inhibiting hypoxia-inducible factor-1 $\alpha$. J Anesth 29: 821-830, 2015.

20. Peng JK, Shen SQ, Wang J, Jiang HW and Wang YQ: Etaypoxia-inducible factor $1-\alpha$ promotes colon cell proliferation and migration by upregulating AMPK-related protein kinase 5 under hypoxic conditions. Oncol Lett 15: 3639-3645, 2018.

21. Li H, Wang X, Wen C, Huo Z, Wang W, Zhan Q, Cheng D, Chen H, Deng X, Peng C and Shen B: Long noncoding RNA NORAD, a novel competing endogenous RNA, enhances the hypoxia-induced epithelial-mesenchymal transition to promote metastasis in pancreatic cancer. Mol Cancer 16: 169, 2017.

22. Livak KJ and Schmittgen TD: Analysis of relative gene expression data using real-time quantitative PCR and the 2(-Delta Delta C(T)) method. Methods 25: 402-408, 2001.

23. Alaseem A, Alhazzani K, Dondapati P, Alobid S, Bishayee A and Rathinavelu A: Matrix metalloproteinases: A challenging paradigm of cancer management. Semin Cancer Biol 56: 100-115, 2019.

24. Zhang W, Zhang JQ, Meng FM and Xue FS: Dexmedetomidine protects against lung ischemia-reperfusion injury by the PI3K/Akt/HIF-1 $\alpha$ signaling pathway. J Anesth 30: 826-833, 2016.

25. Piegeler T and Beck-Schimmer B: Anesthesia and colorectal cancer-The perioperative period as a window of opportunity? Eur J Surg Oncol 42: 1286-1295, 2016.

26. Wigmore TJ, Mohammed K and Jhanji S: Long-term survival for patients undergoing volatile versus IV anesthesia for cancer surgery: A retrospective analysis. Anesthesiology 124: 69-79, 2016.

27. Xie Z: Cancer prognosis: Can anesthesia play a role? Anesthesiology 119: 501-503, 2013. 
28. Terry S, Buart S and Chouaib S: Hypoxic stress-induced tumor and immune plasticity, suppression, and impact on tumor heterogeneity. Front Immunol 8: 1625, 2017.

29. Athanasoula KCh, Gogas H, Polonifi K, Vaiopoulos AG, Polyzos A and Mantzourani M: Survivin beyond physiology: Orchestration of multistep carcinogenesis and therapeutic potentials. Cancer Lett 347: 175-182, 2014.

30. Mobahat M, Narendran A and Riabowol K: Survivin as a preferential target for cancer therapy. Int J Mol Sci 15: 2494-2516, 2014.

31. Rankin EB and Giaccia AJ: Hypoxic control of metastasis. Science 352: 175-180, 2016

32. Li X, Liu X, Xu Y, Liu J, Xie M, Ni W and Chen S: KLF5 promotes hypoxia-induced survival and inhibits apoptosis in non-small cell lung cancer cells via HIF-1 $\alpha$. Int J Oncol 45: 1507-1514, 2014

33. Sun XP, Dong X, Lin L, Jiang X, Wei Z, Zhai B, Sun B, Zhang Q, Wang X, Jiang H, et al: Up-regulation of survivin by AKT and hypoxia-inducible factor $1 \alpha$ contributes to cisplatin resistance in gastric cancer. FEBS J 281: 115-128, 2014.
34. Ai P, Shen B, Pan H, Chen K, Zheng J and Liu F: MiR-411 suppressed vein wall fibrosis by downregulating MMP-2 via targeting HIF-1 $\alpha$. J Thromb Thrombolysis 45: 264-273, 2018.

35. Yang L, Shen L, Li G, Yuan H, Jin X and Wu X: Silencing of hypoxia inducible factor- $1 \alpha$ gene attenuated angiotensin-induced abdominal aortic aneurysm in apolipoprotein E-deficient mice. Atherosclerosis 252: 40-49, 2016.

36. Gu J, Sun P, Zhao H, Watts HR, Sanders RD, Terrando N, Xia P, Maze M and Ma D: Dexmedetomidine provides renoprotection against ischemia-reperfusion injury in mice. Crit Care 15: R153, 2011.

37. Zhang XY, Liu ZM, Wen SH, Li YS, Li Y, Yao X, Huang WQ and Liu KX: Dexmedetomidine administration before, but not after, ischemia attenuates intestinal injury induced by intestinal ischemia-reperfusion in rats. Anesthesiology 116: 1035-1046, 2012.

(i) () () This work is licensed under a Creative Commons C. At No Atribution-NonCommercial-NoDerivatives 4.0 International (CC BY-NC-ND 4.0) License. 